\title{
Community Environmental Knowledge in African Rural Development
}

\section{Paul Richards}

\section{Introduction}

Until recently social scientists working in the Western tradition assumed a basic distinction between the pre-scientific modes of thought characteristic of primitive societies and the rational patterns of thought characteristic of modern technological society. Currently this distinction is maintained with less certainty. Evidence has been presented which shows both that so-called 'traditional' societies have welldeveloped methods of collecting and acting upon empirical knowledge which compare with the methods of organised science, and that symbolic and mystical thought patterns once thought to be the more or less exclusive preserve of preindustrial societies are to be found proliferating in contemporary technologically advanced societies (cf. Horton 1967, Cohen 1974, Barker, Oguntoyinbo and Richards 1977).

The implication of the above is twofold: first that western science may harbour symbolic and rhetorical characteristics at odds with the primary technical and empirical aims of the field of study in question (cf. Koestler, 1959) and second that the thought and knowledge of 'peasant' and 'folk' societies-although perhaps primarily focused on social regulation-may embody content of sufficient empirical and technical merit to be well worth the effort of 'demystification'.

The theme of this paper is that of methodology suitable for investigating and interpreting environmental knowledge in 'peasant' societies in Africa. How can he assess the validity of both components in situations of rapid social and environmental change? It is hoped that answers to questions such as these would lead to an assessment of how much rural communities could be expected to rely on their own knowledge systems for development purposes and of where it is that outside help is most nęeded or would be best applied, either to protect local knowledgegenerating systems and institutions from 'erosion' by external forces and agencies-or to supplement such endogenous systems at identified points of critical weakness. There is also the question of what wider role community expertise-for example in the field of herbal medicine or agriculture-might be able to play in national schemes for environmental research and education.

To focus debate it is intended:

- to briefly describe a study where community environmental knowledge has already proved significant;

--to outline particular methodologies for collecting community environmental knowledge and for evaluating its content;

-to suggest areas and problems within the rural development field where an analysis of community environmental knowledge might be expected to be of maximum benefit.

Community environmental knowledge in Nigeria: the case of the variegated grasshopper

The joint Centre for Overseas Pest Research/ University of Ibadan Zonocerus variegatus study was undertaken at the request of the Nigerian Federal Government with the aim of elucidating the biology and ecology of the Variegated Grasshopper and finding ways of controlling a pest seen as an increasing problem to agricultural communities in southern Nigeria. An ethnoecological study was commissioned to supplement the main scientific research programme and investigations were carried out in twelve different parts of southern Nigeria to assess levels of knowledge concerning the Variegated Grasshopper in typical farming communities in these areas. Results can be classified under four headings:

1. Research team findings transcending local knowledge.

Such results include, for example, findings concerning egg mortality under different temperature conditions, and possible role of chemical attractants in helping create and sustain egg-laying sites. Typically such results depend on precise quantitative data, experimental control and sophisticated biochemical analysis.

2. Areas where community knowledge hinted in general and imprecise ways at results worked out in detail by the project team.

Examples would be the frequent observation that Zonocerus population fluctuations were related to 
climatic anomalies and the feeling that Zonocerus spread correlates with the spread of the herbaceous weed Chromolaena odorata (= Eupatorium odoratum). The farming community's knowledge in these cases appears equivalent to the initial hypotheses scientific work starts with.

\section{Local knowledge equivalent to research team findings.}

Examples include observations concerning the larva of the fly Blaesoxipha filipievi and the fungus Entomopthora grylli as factors influencing mortality amongst Zonocerus populations as the rains begin; Zonocerus food preferences and the general impact of damage to cassava (farmers' estimates of extreme damage $=62.5 \% \pm 16 \%$ yield loss against experimental defoliation damage results c. $60 \%),{ }^{1}$ and the tendency for egg-laying to take place in specific localities in the farm. (Many farmers could describe typical sites, egglaying behaviour and egg pods and a few had anticipated the recommended control strategy of marking out and digging up egg-laying sites).

4. Local knowledge additional to research team findings.

In some cases communities had detailed knowledge not otherwise available to the research team. Typical examples include knowledge relating to dates, severity and geographical extent of specific Zonocerus outbreaks not observed by researchers, and data on the range of crops attacked and local significance of these crops (especially region-specific subsistence crops-e.g. Telfairia occidentalis in eastern Nigeria). An especially important item of local knowledge concerns the fact that Zonocerus (and other grasshoppers) are eaten on a considerable scale in some areas, and even sold in the market place. Survey results indicate some tendency for women, children and poorer people in general to be the greatest beneficiaries of entomophagy. Preliminary inquiries in Sierra Leone suggest that Zonocerus may have figured as an item of diet in other parts of West Africa as well. This raises questions about the appropriateness of uniquely categorising this grasshopper as an agricultural pest.

It is argued that the overlap and complementarity in farmers' and scientists' knowledge concerning the Variegated Grasshopper is to be accounted for by the way observations are made. Thus, for

\footnotetext{
1 Where damage occurs during the normal leaf regeneration period.
}

example, farmers had no type 1 information because of lack of opportunities for precise quantification and analysis of the kind provided by laboratory and microscope. Scientists lacked type 4 information because they were not living as part of the farming community and because recording relevant local ecological detail requires a fine-grained spatial sampling procedure. The adequacies and inadequacies of types 2 and 3 observations and inferences are to be explained in terms of what the farmer can readily see and remember. The life cycle of Zonocerus was likely to be adequately comprehended because the insect is large; feeding, copulation, oviposition, incubation and hatching take place in a restricted compass in and around a single farm field; and fungus attack and Blaesoxipha parasitisation are clearly visible to the naked eye. Below-ground pests such as termites, or microscopic organisms such as nematodes and bacteria, or pests with complex life-cycles involving extensive geographical spread and considerable time spans, e.g. the desert and migratory locusts, are likely to be much less well understood. Even so it is only fair to add that farmers sometimes have surprisingly clear insights based on indirect inference. Many eastern Nigerian farmers hypothesise a connection between rain storms and the spread of Cassava Bacterial Blight. In focusing on heavy rain they have correctly identified rain splash as a major vector by which the causal bacterium is spread through the farm, even though the bacterium itself remains invisible and hence, strictly speaking, unknown.

\section{Methods for collecting and evaluating community environmental knowledge}

In order to develop a critique of this kind of indigenous knowledge it is appropriate to consider

-methods for eliciting what the farmer knows;

- methods for analysing what the farmer knows;

- methods for elucidating the process by which the farmer comes to know what he knows.

A questionnaire approach has much to recommend it provided as Whyte (1977) suggests, it can be reinforced by observation and participation. It is a particularly useful instrument in the context of a well-designed sample survey designed to pick up type 4 information. Proper stratification is an important factor here since knowledge and experience varies according to local ecology and human geography and also according to the age, sex and class affiliations of the individuals concerned. 
A major problem with the questionnaire in this type of work, however, is that according to Whyte (1977) 'the schedule should have its own internal logic' and the respondent 'should be able to see the "sense of it" or he will be confused ...' 'Internal logic' and avoidance of 'confusion' are laudable objectives but the logic is the interviewer's own and may conflict with the purpose of the interview which is not to assemble independent items of information as 'facts' but to lay bare the system of knowledge and structure of ideas which is central to the respondent's own views of the world. Questionnaire users are already familiar with 'leakage' problems whereby a given question can stimulate interest in or heighten awareness of an issue to such an extent that answers to later questions on cognate topics are unreasonably biased. In this particular case we may suspect that an interview schedule, with a strongly articulated internal 'logic' causes a helpful and intellectually agile respondent to suspend the use of his own structures of ideas and temporarily assume a logic imposed on him by the questionnaire.

Evidence that the straight-line logic built into many questionnaires can cause problems is provided by a recent survey of rural development priorities in Sierra Leone. Using a preference scale to indicate feelings about possible rural improvements a number of farmers had scaled their supposed priorities without demur when one, less willing to bow to the implicit rules of the interview schedule than most, turned the question and asked 'if you needed a house which would you rather have-the walls or the roof?' thus making a fairly basic point that 'roads', 'water supply', 'schools' and so on could not be scaled along a single preference priority dimension. To live in a community as opposed to planning for it would make all these individual investments appear part of an interconnected bundle of needs. The point, however, is not about the need for 'integrated' rural development but that only one farmer in the sample was prepared to risk causing offence by stating a point of view which in all probability was obvious to them all.

Community environmental knowledge should be considered along similar lines as an interconnected, multi-dimensional system of data, symbols and values rather than as miscellaneous collection of factual items. Unless there is opportunity for the respondent to make these connections and dimensions clear, his responses, taken at face value and as provoked by the contingencies of a tightly structured questionnaire interview, may unwittingly mislead rather than inform.
An alternative approach is to endeavour to learn the thought patterns of the community concerned from the inside. Participant observation of the necessary depth is often impracticable from the point of view of time and research support available. A more realistic strategy may be to combine some direct observation of the interplay of language, symbol, ideas and action with a 'gaming' approach in which a series of 'let's imagine' situations are set up by the researcher and respondents are asked to act out or talk out the responses likely if the situation had occurred in life. The gamut of possibilities ranges from the highly structured test approach using logical conundrums and pictorial stimulus material of a kind familiar from IQ and thematic apperception tests to much more open-ended devices such as stimulating a discussion by asking someone to tell, or complete, a story or sing a song relating to a give theme of interest. John Gay's work in Liberia is especially notable for emphasis on methods of this latter kind, which nevertheless produce results permitting sophisticated quantitative analysis. Steven Turner (1978) has successfully applied some of Gay's sentence completion methods in a study of soil erosion problems in Lesotho. The advantage of 'ethnotesting' methods of this type is that by having recourse to familiar social situations and settings (e.g. verandah story telling) and to indigenous cultural resources (stories, sayings, proverbs, traditional games, etc.) the interviewer is able to efface himself and his 'internal logic' and hand over the initiative to the respondent in a way not feasible in a conventional 'interview'. An approach in which this kind of interview is combined with days working alongside the farmer in the field, listening to what is being said and experiencing and observing what the farmer experiences, appears to provide real possibilities not only of uncovering what people know and think about their environment but also of giving some clue as to how the components of that thought and knowledge are structured. An example of relevant methodology-the repertory grid-is discussed in greater detail later in this paper. But first it is appropriate to consider two basic ground rules which apply to the question of how the farmer acquires knowledge--how he knows what he knows.

The first is that the farmer will not know that which he cannot observe fully and completely. The case of microscopic entities has already been mentioned. Processes the farmer only witnesses in part such as price determination for commodities sold in remote markets (Filani and 
Richards, 1976), long-term climatic variation (Oguntoyinbo and Richards, 1978), and soil erosion ultimately traceable to the pressures of population or regional development (O'Keefe, 1975) will be understood less well than the range of 'above ground' pest and weed problems which are restricted to the farm field and its immediate locality.

Rule two is that quantitative judgments and farm decisions based on quantification cannot be better than the level of accuracy inherent in the quantitative procedure used by the farmer. It becomes a matter of interest to find out what the farmer measures on his farm and how these measurements are taken.

Many farming procedures have quantification built into the work. Examples are the sections of a yam barn and the regular size and shape of sub-sections within the yam farm (Richards, 1973). Takete Ide farmers (Kwara State, Nigeria) use 7,11 or 15 guinea corn stalks woven together as the basis for a yam vine trellis, each stalk being the starting point for a short row of 10-20 yam heaps (the distance the farmer hoes before straightening up and stretching), the ultimate effect being a series of semi-standard and clearly visible subdivisions within the field analogous to the strips of the medieval European Open Field (Atteh, personal communication, cf. Orwin and Orwin, 1966). Units of this kind can be used in place of a ready reckoner when estimating field size, but since in essence they record the ease or difficulty of cultivation rather than 'area' in a geometric sense they will most probably 'reckon' returns to labour rather than output per unit of land. Output per unit of labour is likely to be the primary concern of the farmer. There will therefore be little point in trying to introduce a land-use intensification to raise output per unit of land unless the farmer can perceive this in his own terms as increased output per unit of labour.

Local units of area, volume, and so on, will have ranges of variation which can be measured and handled statistically. The same applies to farmers' abilities correctly to estimate distances, weights, areas, times required for particular tasks, typical yields per acre and so on (for examples see Richards, 1977; Oguntoyinbo and Richards, 1978). If farmers' estimates of 'perceived production' for a given field are normally distributed with a standard deviation of 20 per cent of the mean there would be at least a one third chance that any improvement up to 20 per cent over previous yields resulting from introduction of an innovation would be undetectable. It is to determine the farmers' sensitivity to changes of this kind that further analysis of indigenous quantification would be desirable (cf. the important pioneer study by Gay and Cole, 1967).

Turning now to the topic of repertory grid methodology as one possible way of eliciting community environmental knowledge and uncovering its structural integrity some simple field examples will illustrate points of methodology made so far.

The basic elicitation procedure is that of the Triads Test in which farmers are presented with 'elements'-mostly concrete objects such as weeds, pests, rice varieties, or grain-legume seeds -in sets of threes and asked to discriminate by pairing two on the basis of similarity and isolating the third on the basis of difference. Respondents are then asked to explain the 'construct' underlying their discrimination, and where appropriate, other objects under consideration are scaled according to this particular construct. The test is repeated until combinations amongst a given set of objects are exhausted and a complete classification of the objects under scrutiny personal to the respondent is created. This is the repertory grid which forms the basis for subsequent analysis.

Table 1 is an extract from a grid from Mayogba in Sierra Leone in which a variety of grain legume seeds were the objects of interest.

This particular trial confirmed that farmers had no difficulty understanding and performing the basic test. The results uncovered points that would almost certainly have been missed in a conventional interview: for example the farmer interviewed in Table 1 recognised 'utilities' beyond feeding and cash income (the brightly coloured seeds of Abrus precatorius are used as gambling chips, for example, and as children's playthings); and a distinction was maintained between personal utility and utility to children. But since some 'marginally' cultivated grain legumes (e.g. Canavalia rosea) and some highly poisonous species (e.g. Physostigma venenosum; Abrus precatorius) were included we had hoped to draw out a few more insights than eventually emerged. Physostigma and Canavalia were not well known and had to be dropped from the test. On the other hand the lack of awareness of the poisonous properties of $A b r u s$ seeds and the fact that they are regarded as children's playthings is 'negative' information of some potential importance. In general, however, this first test was only partly successful because the set of objects used had been predetermined. 
Table 1

\begin{tabular}{|c|c|c|c|c|c|}
\hline SEED CONSTRUCT & Abrus sp. & Mucuna sp. & Phaseolus sp. & Vigna sp. & Delonix sp. \\
\hline Food/non food & $0+$ & $0^{*}$ & $1 *$ & $1 *$ & $0+$ \\
\hline Income/no income & $0+$ & $0 *$ & $1 *$ & $1 *$ & $0+$ \\
\hline Weed/not weed & $1+$ & $1 *$ & $0^{*}$ & $0 *$ & $0+$ \\
\hline Shade/no shade & $0+$ & $0^{*}$ & $1 *$ & $1+$ & $1 *$ \\
\hline $\begin{array}{l}\text { Utility for children/no utility } \\
\text { for children }\end{array}$ & $1^{*}$ & $0^{*}$ & $1+$ & $1+$ & $1^{*}$ \\
\hline $\begin{array}{l}\text { Utility for farmer/no utility to } \\
\text { farmer }\end{array}$ & $0^{*}$ & $0+$ & $1 *$ & $1+$ & $1 *$ \\
\hline Games/no games & $1 *$ & $0+$ & $1^{*}$ & $1+$ & $1^{\text {s }}$ \\
\hline
\end{tabular}

* species used to elicit the construct under consideration

+ species coded subsequent to construct elicitation

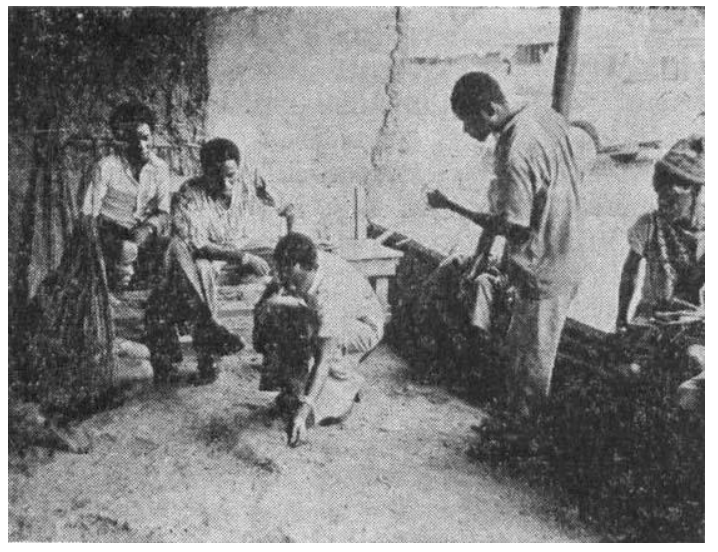

(Photo: P. Richards)

Farmers participating in a repertory grid test concerning local weeds, Mayogba, Sierra Leone.

Better results were obtained when the farmers themselves defined the 'sample frame'. Initial trials with a set of locally important weeds proved more satisfactory, particularly as it was possible to carry out trials on university students and extension officer trainees at the same time using the same set of weeds. Even very small grids proved interesting. When the following four weeds were considered:

\section{Calopogonium mucunoides \\ Mimosa pudica \\ Sida stipulata \\ Ageratum conyzoides}

farmers' constructs brought out the secondary medicinal uses of Sida and Ageratum, ${ }^{2}$ the extreme difficulty of clearing associated with Mimosa and Calopogonium and the tendency for very troublesome weeds e.g. Calopogonium to be assimilated to the Mende concept of 'pest'. Sierra Leonian university botany and geography students not surprisingly produced grids which reflected a preoccupation with morphology and Linnean taxonomy rather than utility and difficulty of elimination. The surprise was that extension trainees produced grids almost identical to those of the university students with constructs such as root/non-root; round leaf/multiple leaf; hair on steam/no hair on stem; hairs on leaf/no hairs on leaf predominating. This proved to be of significant 'diagnostic' value, leading to a spontaneous 'seminar' by the trainees on how they would communicate with farmers if their 'scientific' approach to farming made them think in text-book botanical terms rather than in terms of farming utilities. Tentative action proposals for syllabus development and for studying alongside the farmers were beginning to emerge at the end of the period. This proved a good illustration of the possibility in development-oriented work on environmental perception of returning to some of the original 'self-analytic' and 'therapeutic' intentions of grid analysis (Kelly, 1955). Work is in progress to build up sets of grids relating to 'indigenous' classification of local rice varieties so that these can be matched against 'constructs' held by rice breeding programme experts. Meanwhile Table 2 is included to illustrate differences that can arise when a farmer and his wife classify

2 Ageratum conzoides is widely used as a means of treating minor wounds and ulcers, see Usher 1974. 


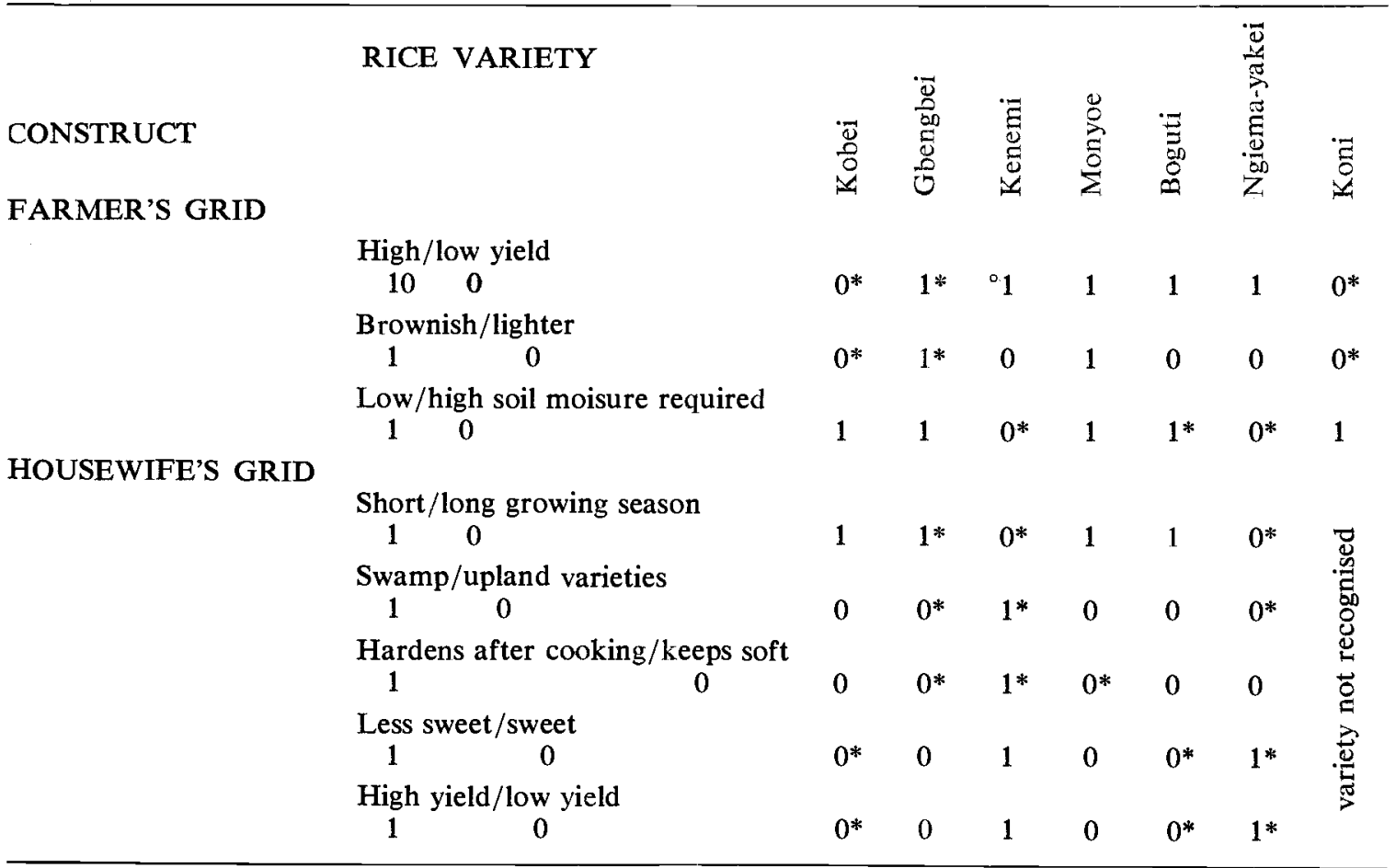

familiar objects-in this case, six Mende upland rice varieties. 'Inside' knowledge concerning taste and edibility is apparent in the wife's grid, pointing to the potential value of the Triads Test in eliciting functionally determined variations of this kind.

Methods for analysing grid information are discussed elsewhere (Barker and Richards, 1978; cf. Barker, 1978; Chapman, 1978; Fransella and Bannister, 1977). It is more appropriate to this paper to discuss the context where this sort of information might be a useful input into the rural planning and development process.

The utility of community environmental knowledge in rural development contexts

Repertory grid techniques and similar approaches appear to have considerable utility (a), in bringing out the multi-dimensional nature of community environmental knowledge, for instance, where there is a utility dimension to a plant or insect normally considered a weed or pest; or where evaluations differ as between men, women, children or between different class and occupational groups such as farmers on the one hand and extension agents on the other; (b) in triggering off useful discussion and self-diagnosis, leading to heightened awareness of variations in response between individuals or groups and to proposals for minimising the conflict and misunderstanding engendered. There is a danger that a great deal of rural development work may undermine what the farmer is attempting to achieve or fuel emerging class conflict by built-in scale and technology biases. 'Conscientisation' (Freire, 1972) may be as necessary in technical areas of agricultural development as in socio-political areas. It is suggested that the approaches outlined in this paper have a good deal to offer where there is genuine determination to 'democratise' development planning and the rural education process and where 'participatory' styles of environmental resource management are the ultimate aim.

Examples and instances, have already been indicated but it may be valuable to spell out both the kinds of problems and the contexts where this kind of approach might be beneficial.

The first and perhaps critical question is if African peasant farmers were capable of managing their environmental resource base and responding to environmental changes in the past 
why are they increasingly incapable of doing so now? Is this because the planner has too low an expectation of what farmers can achieve for themselves or because the problems and issues are now on a different and much less readily manageable scale than previously? Or could it be that 'agricultural science', and the key role assigned to the 'expert', are essential elements in establishing technocratic hegemony in furtherance of the interests of 'agri-business' or 'state capitalism' within the development process?

If so, then the least that might be expected from dialectically opposed emphasis on indigenous knowledge-ethno-science-is that it would help deflate the rhetorical humbug of 'modernisation' theory or its socialist-technocratic equivalent. On the other hand the epistemology will have to be rigorous-a sentimental belief in 'traditional values' and a gut feeling that the 'people know best' without knowing why and under what circumstances, will be equally unhelpful and damaging to the prospects for rural development in the long run.

But granted a properly founded understanding of peasant farmer knowledge formation and of the structural inequalities and problems likely to result from 'technology transfer' where the organised knowledge 'industry' interfaces with the small-scale 'informal' world of African rural societies, it should prove possible to plan for action in the following areas:

Preservation of valuable local knowledge and attitudes relating to the agricultural environment

Many 'traditional' beliefs and attitudes to environmental resources are oriented to conservation rather than exploitation. A valid critique would have to take into account land tenure practices and how such practices are changing. In the African context a surface rhetoric of communalism often masks a complex and ramifying pattern of private ownership with marked inequality in access to agricultural resources. How much this influences technical knowledge relating to soil and vegetation and to what extent the local ethno-science is 'distorted' as a result is open to question. Field experience suggests that even if local knowledge of soil fertility, erosion, weed growth, etc., were 'edited' to allow for such biasing effects, much of value would remain. Documentation and preservation of such knowledge as a record of human achievement would be worthwhile in itself. Incorporating such perspectives into school curricula and into training programmes for rural extension and community development workers would have the advantage of creating mutual respect across the generations and between farmers and technical specialists, thereby facilitating effective communication and co-operation at local level. The introduction of farmers' perspectives, locally 'relevant' problems and the best of indigenous knowledge into African school syllabuses and textbooks is curently being undertaken by a number of individuals and organisations (for example, the Science Education Programme for Africa [SEPA] in Accra, the Environmental Review Unit of the International African Institute in London and the Training for Environment Programme [ENDA] in Dakar).

\section{Utilisation of local skills and man-power for environmental monitoring and management}

The Zonocerus study indicated the possibility that in certain definable but limited areas of competence farmers were likely to be capable of:

-monitoring a problem so as to provide a valuable cost-effective input into a scientific research programme;

-overcoming problems either on their own initiative or with a modicum of outside assistance of a catalytic nature.

This latter point has to be put to the test in the context of a formal pest control programme (Page and Richards, 1977) but if such a programme proves successful it would open the door to a number of other ventures of a similar kind. Locust control work has long made use of a local reporting network to provide detailed day to day information on insect incidence and behaviour, and generalising this idea to cover a wide range of pest and weed problems at farmer level might be a valuable step forward. Barker et al. (1977) have proposed two versions of a model monitoring system using farmers as primary reporters. Oguntoyinbo and Richards (1978) suggest extending this idea to drought monitoring work. Ford (1971) has argued the case that "hightechnology' trypanosomiasis control may have interfered with the low-level 'adaptations' individual communities were able to attain in the past and that awareness of the extent to which the colonial presence undermined these effective precolonial man-environment adaptations ought to stimulate a major reconsideration of sleeping sickness control strategies and priorities. Along rather similar lines Agarwal (1978) has summarised growing concern that conventional pesticidal and drug-based approaches to the malaria 
problem are beginning to break down, raising the question as to whether old-fashioned 'propaganda' methods aimed at involving the total population in trying to control mosquito breeding or reduce the chances of being bitten might not prove the key to the long-term solution. If so, ethnoscientific studies of local knowledge concerning mosquitos and malaria, with the eventual aim of building on what people already know and filling in crucial gaps, might prove of special importance.

\section{Strengthening diagnostic and analytical abilities at the local level}

An implied 'working hypothesis' comes to the fore in this context-namely that many African environmental problems are 'problems' because 'specialisation' implicit in development generates new or more marked sets of vested interests which traditional processes of consultation and conflict resolution are powerless to mediate. A community divided against itself may accept the imposition of outside 'technical' solutions on increasingly unfavourable terms. For example a structural problem in the land allocation system may reach a short-term solution through application of government-subsidised fertiliser to overworked holdings. Whether the solution holds up when farmers have to pay the full world price at 'energy-crisis' rates of inflation is open to question. Meanwhile the opportunity to grasp the more basic problem of political economy may have gone by default. The self-diagnostic and internal consciousness-raising attributes of a wellarticulated and democratically structured progranme in 'peoples' science' could have considerable potential in this difficult area of 'community development', and might lead to some interesting endogenous experiments in restructuring manenvironment relationships in rural areas experiencing rapid economic transformation.

\section{References}

Agarwal, A., 'Malaria makes a comeback', New Scientist, 77, no 1088: 274-276, 2 Feb. 1978

Barker, D., 'Some methodological issues in the measurement analysis and evaluation of peasant farmers' knowledge about the environment', Research Memorandum, MARC, Chelsea College, London 1978

Barker, D. and P. Richards, 'Repertory Grid methods and environmental images in rural Africa', Inst. Br. Geogr. Quantitative Methods and Developing Areas Study Group Joint Meeting, SOAS, 18 March, 1978
Barker, D., J. S. Oguntoyinbo and P. Richards, The Utility of the Nigerian Peasant Farmer's Knowledge in the Monitoring of Agricultural Resources, General Report 4, MARC, Chelsea College, London, 1977

Chapman, N., 'Preliminary study of the effects of agricultural extension on farmers' images', Geography Dept., University of Calabar, 1978 (mimeo)

Cohen, A., Two-dimensional Man, University of California Press, Berkeley, 1974

Filani, M. O. and P. Richards, 'Periodic market systems and rural development: the Ibarapa case study, Nigeria', Savanna, 5: 149-162, 1976

Ford, J., The Role of the Trypanosomiasis in African Ecology, Clarendon Press, Oxford, 1971

Fransella, F. and D. Bannister, A Manual for Repertory Grid Techniques, Academic Press, London, 1977

Freire, P., Pedagogy of the Oppressed, Penguin Books, Harmondsworth, 1972

Gay, J. and M. Cole, The New Mathematics and an Old Culture: A study of learning among the Kpelle of Liberia, Holt, New York, 1967

Horton, R., 'African traditional religion and Western science' Africa, 37, (2 parts), 1967

Kelly, G. A., The Psychology of Personal Constructs (2v.), Norton, New York, 1955

Koestler, A., The Sleepwalkers, Hutchinson, London, 1959

Oguntoyinbo, J. S. and P. Richards, 'Drought and the Nigerian farmer' Journal of Arid Environment, 1: 165-194, 1978

O'Keefe, P., Gakarara-a study in the development of underdevelopment, unpublished Ph.D. thesis, London, 1975

Orwin, C. S. and S. Orwin, The Open Fields, Clarendon Press, Oxford, 1966

Page, W. and P. Richards, 'Agricultural pest control by community action: the case of the Variegated Grasshopper in southern Nigeria', African Environment, 2 and 3: 127-141, 1977 
Richards, P., 'Space as an idea' Geography Dept., University of Ibadan, 1973 (mimeo)

Richards, P., Ideas, environment and agricultural change: a case-study of peasant farming from western Nigeria, unpublished Ph.D. thesis, London, 1977

Turner, S., Lesotho Farming: the condition and prospects of agriculture in the lowland and foothills of Lesotho, unpublished Ph.D. Thesis, London, 1978

Usher, G., A Dictionary of Plants Used by Man, Constable, London, 1974

Whyte, A., Guidelines for field studies in environmental perception, MAB (Man and the Biosphere) Technical Notes 5, UNESCO, Paris, 1977 